Gazi Mühendislik Bilimleri Dergisi

2020, 6(3): 172-183

Araștırma Makalesi/Research Article https://dergipark.org.tr/gmbd

\title{
Yerel İkili Desenler Histogramları ile Covid-19 Tanılı Kişiler Üzerinde Kimlik Analizi ve Bildiri Sistemi
}

\author{
Nuray KARADAĞ $\breve{G}^{\mathrm{i}}$, Ali ÇETINKAYA*b iD, Hakan AYDIN ${ }^{c}$ id \\ ${ }^{a}$ İstanbul Gelişim Üniversitesi Bilgisayar Mühendisliği Bölümü, 34310, ISSTANBUL, TÜRKIYYE \\ ${ }^{b,{ }^{*}}$ İstanbul Gelişim Üniversitesi Teknoloji Transfer Ofisi Uygulama ve Araştırma Merkezi, 34310, ISTANBUL, TÜRKIYE
}

${ }^{c}$ İstanbul Gelişim Üniversitesi Bilgisayar Mühendisliği Bölümü, 34310, ISTANBUL, TÜRKIYYE

MAKALE

BÍLGISİ

Alınma: 18.08.2020

Kabul: 20.12 .2020

Anahtar Kelimeler:

Yüz Tanıma,

Kimlik Analizi,

Covid-19,

LBPH

*Sorumlu Yazar:

e-posta: alcetinkaya@

gelisim.edu.tr
ÖZ

\begin{abstract}
Günümüzde birçok alanda kullanılan yüz tanıma sistemlerine işlevsellik katılarak varolan yüz tanıma sistemlerinden daha farklı bir sistem geliştirilmesi amaç edinilmiştir. Son zamanlarda Covid-19 pandemisi ile birlikte sokağa çıkma yasakları ve bu yasakların kontrolünde çekilen zorluklar göz önüne alınmış ve azaltılması amacıyla bu sistem geliştirilmiştir. Sistemde veri setinde kayıtlı Covid-19 tanılı kişinin sokağa çıkmasıyla kamera tarafından görüntülenmesi üzerine yetkili kişi veya kişilere e-posta gönderildiği bir çalışma gerçekleştirilmiştir. Tasarlanan yazılımda ilk önce Haar-Cascades sınıflandırıcısı ile yüzü algılayıp sonra LBPH (Yerel İkili Desenler Histogramları) yöntemi kullanılarak yüz tanıma işlemi gerçekleştirilmektedir. Bu işlem tanıtılan görüntünün her pikselini, etrafındaki diğer piksellerle eşleyerek etiketleme yapılması ile gerçekleşir. Bu etiketlemenin sonucu ikili sayı sistemine dönüştürülerek saklanır. Gerçek zamanlı olarak kameradan aldığı görüntüleri bu sayı ile karşılaştırarak yüzü tanımaya çalışır. Tanıma işleminde eğer kişi veri setinde daha önce kayıtlı ise "kırmızı" renkli çerçeveye alınır. Kayıtlı değilse "yeşil" renkli çerçeve içerisine alınır. Kamera tarafından tanınan kırmızı çerçeveli kişiler görüldügü saat, tarih ve kimlik bilgisiyle yetkili kişilere bildirilir. Çalışma, 90 frame baz alınarak $\% 84,5$ başarı oranı, \%15,5 hata oranına sahiptir.
\end{abstract}

\section{Identification Analysis and Reporting System on People with Covid-19 Diagnosis with Local Binary Patterns Histograms}

\section{ARTICLE \\ INFO \\ Received: 18.08 .2020 \\ Accepted: 20.12.2020 \\ Keywords: \\ Facial Recognition, \\ Identity Analysis, \\ Covid-19, \\ $\mathrm{LBPH}$ \\ "Corresponding \\ Authors \\ e-mail: alcetinkaya@ \\ gelisim.edu.tr}

\begin{abstract}
It is aimed to develop a different system than existing facial recognition systems by adding functionality to facial recognition systems used in many areas today. Recently, with the covid-19 pandemic, curfews and difficulties in controlling these bans have been taken into account and this system has been developed to reduce them. A study was carried out in which an email was sent to the authorized person or persons after the Covid-19 diagnosed person registered in the data set in the system was viewed by the camera when he went out on the street. In the designed software, face recognition is first performed using the Haar-Cascades classifier and then using the LBPH (Local Binary Patterns Histograms) method. This process occurs by tagging each pixel of the introduced Image by mapping it to other pixels around it. The result of this labeling is stored by converting it to a binary number system. He tries to recognize the face by comparing the images he receives from the camera in real time with this number. During the recognition process, if the person was previously registered in the data set, they are taken into the "red" color frame. If not registered, it is enclosed in a "green" colored frame. People with red frames recognized by the camera are notified to authorized persons by the time, date and identification information they are seen. Based on 90 frames, the study has a success rate of $84.5 \%$ and an error rate of $15.5 \%$.
\end{abstract}

Bu makaleye atıf yapmak için: N. Karadă̆, A. Çetinkaya ve H. Aydın, "Yerel İkili Desenler Histogramları ile Covid-19 Tanılı Kişiler Üzerinde Kimlik Analizi ve Bildiri Sistemi," Gazi Mühendislik Bilimleri Dergisi, cilt 6, sayı 3, s. 172-183, Aralık, 2020, doi: https://dx.doi.org/10.30855/gmbd.2020.03.01. 


\section{INTRODUCTION (GiRIŞs)}

$\mathrm{Bu}$ çalışmada, yüz tanıma sistemlerinin genel yapısı incelenmiş ve inceleme sonucunda pratik bir yüz tanıma sistemi geliştirilmiştir. Geliştirilen yüz tanıma sistemi ile kameradan anlık olarak kişilerin yüzlerinin tanınması ve Covid-19 tanılı kişilerin kimlik analizinin yapılması sonucunda sistem tarafindan yetkili kişilere e-posta ile bilgi verilmesi sağlanmıştır. Bu şekilde virüsün yayılmasının kontrol altına alınması amaç edinilmiş̧ir.
COVID-19, ilk olarak Çin'de 13 Ocak 2020'de tanımlanan bir virüstür. Koronavirüsler; tek zincirli, zarflı RNA virüsleri dir. En belirgin belirtileri ise ateş, öksürük ve nefes darlığıdır. İnsanlarda ve hayvanlarda hastalığa neden olurlar. Hasta kişilerin öksürmeleri ile ortama saçılan damlacıklar ve kirlenmiş yüzeylerle temas eden kişilere bulaşabilmektedir [1, 2]. COVID19 tanılı hasta, evdeki izlem süresinde dışarı çıktığında cezai sorumluluğu vardır. Evde karantina süresince İl Sağlık Müdürlükleri tarafindan telefonla takip edilmesi gerekmektedir [3].
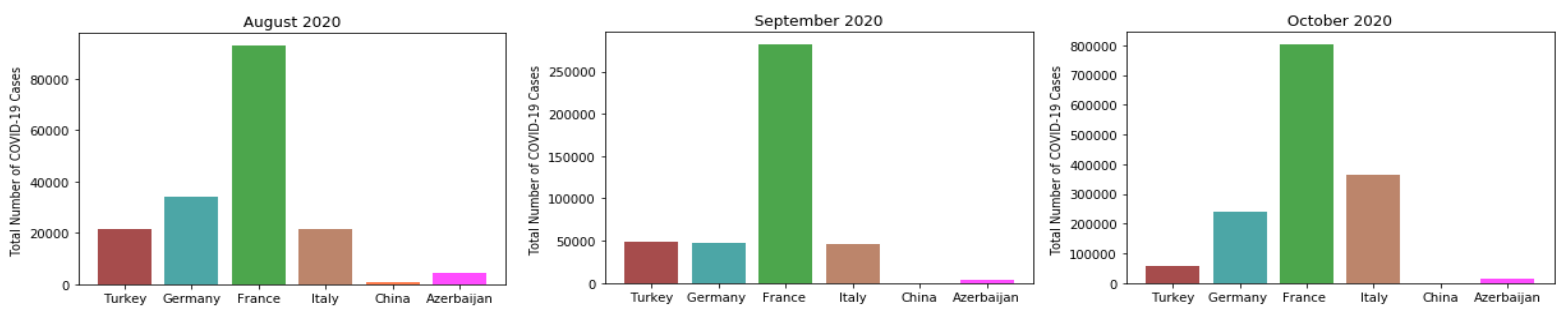

Şekil 1. Ağustos, Eylül ve Ekim aylarına ait koronavirüs vaka sayılarının grafiği(Graph of coronavirus case numbers for August,September and October.)

Şekil 1'de ülkemiz ve dünya üzerindeki bazı ülkelerin Ağustos, Eylül ve Ekim ayı içerisindeki koronavirüs (Covid-19) vaka sayıları verilmiştir [4, 5]. Koronavirüs vakalarının ilki Çin'de görülmüştür. Çin Hükümeti güncel teknolojiyi sağlık alanına entegre ederek Covid-19 tanılı hastaların kimlik bilgileriyle, kimlik üzerinde bulunan fotoğraflarının eşleşmesi ve büyük veri tabanlarına kaydedilmesi sonucunda hasta kişiyle temas etmiş diğer bireyleri rahatlıkla tespit edip, salgını kontrol altına alabilmektedir. Kiminle temas ettiklerinin analizi şu şekilde yapılmaktadır; tüm vatandaşların sokağa çıkmadan önce kapılarının önünde bulunan yüksek çözünürlüklü kameradan yüzlerini tanıtmaları istenmektedir ve bu şekilde yüzü tanınan vatandaşlar diğer kameralarca takip edilip kimlerle temas ettiği belirlenmektedir. Çalışmamız bu sistemden esinlenilerek geliştirilmiştir.

$\mathrm{Bu}$ çalışma altı bölüm halinde düzenlenmiştir. Birinci bölümde, klasik yöntemler kapsamında yüz tanıma sistemlerinin temelleri ve Covid-19 virüsü hakkında bilgiler sunulmuştur. İkinci bölümde, daha önceki yüz tanıma sistemleri hakkında literatür çalışmaları değerlendirilmiştir. Üçüncü bölümde ise LBPH algoritmasının çalışma mantığ 1 ve veri setinin nasıl oluşturulduğu anlatılmıştır. Dördüncü bölümde, uygulamanın çalışması ve yapılan işlemlerin ayrıntılarına yer verilmiştir. Beşinci bölümde ise yapılan deneyler yer almaktadır. Son olarak altıncı bölümde ise sistem hakkında tartışma ve önerilerden bahsedilmiştir.

\section{2. İLGİLI ÇALIŞMALAR (RELATED WORKS)}

Sağlık, robotik ve savunma sanayiindeki gelişmeler incelendiğinde yapay zekanın önemli bir alan olduğu ve bu alanda daha çok çalışma yapılması gerektiği anlaşılmaktadır [6]. Yapay zeka alanında görüntü analizi [7-9], biyometrik tanıma sistemleri [10], hayvanlarda yüz analizi [11], plaka tanıma [12], zatürre hastalığının teşhisi [13], yüz tespiti [14-17], yüz analizi [18, 19], yüz kimlik doğrulama sistemi [6, 20], cinsiyet tanıma sistemi [21], elektronik sistemler [22, 23], ekonomik işlemlerin analizi [24, 25], tanımlama ve tahmin [26] gibi çalışmalar yapılmıştır.

Gerçek zamanlı yüz tanıma sistemi iki farklı platformda tasarlanmıştır [15, 16]. Tasarlanan sistemde makine öğrenimi ve derin öğrenme tekniklerinin karışımı kullanılmış̧ır [27]. Derin öğrenme teknikleri ile sabit olmayan nesnelerin tanınma ve takibi için kullanılmıştır [28]. Aynı zamanda Google'ın kütüphanesi TensorFlow kullanılmış ve son olarak nesnelerin takip edilmesi için ise RBCN den Faster R-CNN modellerinden 
yararlanılmıştır [29]. Günümüzde yaygın olarak kullanılan kartlı takip sistemlerinin güvenlik zafiyetleri bulunmaktadır. $\mathrm{Bu}$ sistemlerin açığını kapatmak için yüz tanıma tabanlı bir sistem geliştirilmiştir [27]. 3170 eğitim verisi ile birlikte 318 test verisi üzerinde çalışılmış ve model için Alex Net ile VGG-16 kullanılmıştır [21]. Bir başka çalışmada 10 milyon görüntü üzerinden bir veri kümesi eğitilmiştir [30]. Derin öğrenmede yüz tanıma sistemleri için kullanılan veri tabanlarında var olan bozulmaların giderilmesi için OpenFace, VGGFace2 ve ARCFACE gibi modeller sistematik olarak kullanılmaya başlanmıştır. Evrişimsel Sinir Ağlarının mimarilerinden biri olan VGG-16 mimarisi ile CPU yerine GPU kullanılmasının bir dönüm noktası olduğu vurgulanmıştır ve bununla birlikte eğer CPU ya da GPU ya sahip değilseniz Google COLAB kullanılması tavsiye edilmiştir [31].

Bu çalışmalar değerlendirildiğinde, VGGFace2 ve ARCFACE modellerinin en doğru sonucu veren güncel modeller olduğu analiz edilmiştir. Aynı zamanda Google COLAB gibi yeni teknolojilerin kullanımı görüntü işlemi ile ilgili çalışmalarda verimlilik sağlamaktadır. Buna ek olarak kullanılan veri sayısı ne kadar arttırılırsa sistemlerin doğruluk oranı da o kadar artar ancak test verisi arttırılsa bile yüz tanıma sistemlerinin tek başına yeterli olmayacağı bunun yanında iris tanımasının yapılmasının en doğru ve güvenli yöntem olduğu analiz edilmiştir.

\section{MATERYAL VE YÖNTEMLER (MATERIALS AND METHODS)}

\section{1. Çalışmada Kullanılan Yöntemler (Methods Used in the Study)}

Çalışmamızda yüz tanıma sisteminin işleyişinden, kullanılacak veri setinin nasıl oluşturulduğundan ve bu tür sistemlerin güvenlik açıklarından bahsedilmiştir. Çalışmada birçok kütüphane ve algoritma kullanılmıştır. Çalışmamızın ilk kısmı, kişinin tanıtılmasıdır. Öncelikle bu adımda kamera açlarak anlık görüntü içerisinde bir yüzün var olup olmadığ 1 analiz edilmektedir. Yüz tespiti sirasında önemli olan gözler, kaşlar, burun ve ağızdır. Bunları algoritma tespit ederek yüz olduğunu anlamaktadır Bir yüz tespit edildiğinde çerçeve içerisine alınmaktadır. Tespit edilen yüz, belirlenen frame sayısı kadar fotoğraflanıp kırpılarak, renkli tonlamadan gri tonlamaya dönüştürülüp veri tabanına kaydedilmektedir ve bu şekilde ilk kısım tamamlanmaktadır.

Çalışmamızın ikinci kısmında ise kaydedilen fotoğraflardan yüzü tanımlayan bir öznitelik vektörü algoritma tarafından çıkarılmaktadır başka bir deyişle kaydedilen yüze belirli bir değer verilmektedir ve bu şekilde ikinci kısım tamamlanmaktadır. Çalışmamızın son kısmında ise bu öznitelik değeri isimlendirilerek tekrar kameradan görüntü alındığında, bu görüntünün değerinin veri tabanında olup olmadığını kontrol edilmektedir. Aynı değer varsa kişiyi tanıyarak ismini yazmaktadır. Eş zamanlı olarak yüz tanındığı için yetkili kişilere anlık saat, tarih ve kimlik bilgileri eposta olarak gönderilmektedir ve bu son kısım da bu şekilde tamamlanmaktadır.

Yapay sinir ağı (YSA), gerçek sinir ağının yapısını, fonksiyonlarını baz alan bir hesaplama modelidir. YSA üstünden taşınan veriler YSA'nın işleyişini etkilemektedir. Bununla birlikte girdiler, çıtılar ve gizli katmanlar ile yapay sinir ağı temeli kurulmaktadır. Tasarlanacak YSA üzerinde belirlenecek matematiksel model ile giren ve çıkan verilerin yönetilmesini sağlanmaktadır. Girdiler işlenmemiş verilerdir. $\mathrm{Bu}$ verileri YSA içerisinde ağırlıklar ile işleyerek YSA'nın öğrenmesi sağlanmaktadır. Aktivasyon fonksiyonları girdiler ve ağırlıklar ile YSA'nın çıktısını belirleyecek bir denklemdir. YSA üzerinde hücreye girecek olan net girdiyi Tablo 1 üzerinde verilen matematiksel tanımlar ve formülleri ile hesaplanmaktadır. Buradan gelen bilgi kendi üzerinde tanımlanan ağırlık ile çarpılarak tanımlı aktivasyon fonksiyonu ile işlenmektedir.

Tablo 1. Yapay sinir ağının hesaplanması için fonksiyonlar (Functions for the calculation of the artificial neural network)

\begin{tabular}{|l|l|}
\hline Toplam & NET $=\sum_{i}^{n} \mathrm{w}_{\mathrm{ij}} \mathrm{x}_{\mathrm{i}}+\theta_{\mathrm{j}}$ \\
\hline Çarpım & $\mathrm{NET}=\prod_{\mathrm{i}} \mathrm{w}_{\mathrm{ij}} \mathrm{x}_{\mathrm{i}}$ \\
\hline Minimum & $\mathrm{NET}=\operatorname{Min}\left(\mathrm{w}_{\mathrm{ij}} \mathrm{x}_{\mathrm{i}}\right)$ \\
\hline Maksimum & $\mathrm{NET}=\mathrm{Max}\left(\mathrm{w}_{\mathrm{ij}} \mathrm{x}_{\mathrm{i}}\right)$ \\
\hline Çoğunluk & $\mathrm{NET}=\sum_{i}^{n} \operatorname{Sgn}\left(\mathrm{w}_{\mathrm{ij}} \mathrm{x}_{\mathrm{i}}\right)$ \\
\hline
\end{tabular}

Aktivasyon fonksiyonu, giriş ve çıkış katmanı arasında eğimsel olarak ilişkilendirilmesi konusunda fayda sağlamaktadır. Doğru fonksiyonu seçebilmek sistemin başarısının büyük kısmını etkilemektedir. Fonksiyon -1 ile +1 aralığında tek ve çift yönlü aynı zamanda eğimli olmayan bir şekilde seçilmelidir. 
Ağda bulunan eğimli olan ağın öğrenmesi aşamasını amaçlayan segmenttir.

Tablo 2. Sigmoid aktivasyon fonksiyonu (Sigmoid activation function)

\begin{tabular}{|c|c|c|}
\hline Aktivasyon Fonksiyonu & Fonksiyonun Gösterimi & Fonksiyonun Formülü \\
\hline Sigmoid & $\boldsymbol{\sigma}$ & $\boldsymbol{1}$ \\
\hline
\end{tabular}

Yapay sinir ağlarında en çok kullanılan sigmoid aktivasyon fonksiyonunun matematiksel ifadesi ve görseli Tablo 2 üzerinde gösterilmiştir. Çıktı, aktivasyon fonksiyonunun sonucunda çıkan değerlerdir. Bu çıktı ya YSA nın çıktısı olarak kabul edilir ya da tekrar ağın içinde kullanılır. Her hücrenin her zaman tek çıktısı olabilir ve bu çıktı istenilen sayıda hücre ile bağdaştırılabilir. $\mathrm{Bu}$ işlemlerin sonucunda YSA kullanılmış, eğitimler gerçekleşmiş ve veriler elde edilmiş olur. $\mathrm{Bu}$ şekilde YSA öğrenmesi gerçekleşir [32].

Derin öğrenme teknikleri kullanılarak kimlik tespit uygulamasının işleyişi ise kullanıcıdan alınan yüz görüntüsü veri seti ile karşılaştırılıp kullanıcının kimlik tespiti rahatlıkla yapılabilmektedir. İnsanlar yüz tanımayı her gün otomatik ve pratik olarak çaba harcamadan yapabilirler. Bizim için çok basit bir görev gibi görünsede, bilgisayarlar için karmaşık bir görev olduğu söylenebilir çünkü yöntemlerin doğruluğunu bozabilecek birçok değişken vardır. Bunlardan bazıları; aydınlatma koşulları, düşük çözünürlük ve oklüzyondur.

Derin öğrenme yapısı içerisinde yer alan modeller de AlexNet, ZFNet, VGG-16, RestNet gibi birçok model ismi sıralanabilmektedir. Evrişimsel sinir ağ1 (ESA), tamamen bağlı bir katmanı takip eden birçok alt katmandan meydana gelir [33, 34]. Kullanılan bu model yapıları sinir ağının eğitimi ve öğreniminde aktif rol oynamaktadır. Kullanılan bu model yapılarının önemi oldukça yüksektir. Bu modeller kullanılarak kişilerin emeklilik fonları yüksek doğruluk oranıyla rahatlıkla tahmin edilebilmektedir [26].

LBP (Local Binary Pattern) görsel bir tanımlayıcı olduğu için yüz tanıma görevleri için kullanılmaktadır. LBP operatörü, gri-seviyeden bağımsız bir doku ölçümü yöntemidir. LBP operatörü görüntünün her pikseli için bir etiket oluşturmaktadır. $\mathrm{Bu}$ etiket merkez pikselin $3 \times 3$ komşuluğundaki piksellerle karşılaştırılması sonucu elde edilen ikili bir sayıdır [35]. Denklem 1 ve 2'de LBP denklemi verilmiştir.

$$
\begin{aligned}
& L B P_{P, R}\left(x_{C}\right)=\sum_{p=0}^{P-1} u\left(x_{p}-x_{c}\right) 2^{p} \\
& u(y)= \begin{cases}1, & y \geq 0 \text { ise } \\
0, & y<0 \text { ise. }\end{cases}
\end{aligned}
$$

Denklem 1 üzerinde verilen $\mathrm{LBP}_{\mathrm{P}, \mathrm{R}}$ değișkeni LBP operatörünü, $\mathrm{x}_{\mathrm{C}}$ değişkeni LBP etiketi üretilen merkez pikseli, $\mathrm{x}_{\mathrm{p}}$ değişkeni merkez pikselin komşularını, $\mathrm{R}$ komşuların merkeze olan uzaklığını ve $\mathrm{P}$ değişkeni ise işleme sokulan komşuların sayılarını temsil etmektedir [20, 35-37].

Gri seviye eş oluşum matrisi belirli bir ofsetle birlikte oluşan piksel değerlerinin (gri tonlama değerleri veya renkler) dağılımı olarak bir görüntü üzerinde tanımlanan bir matristir. LBP'ler yerel bir doku temsilini hesaplar. $\mathrm{Bu}$ yerel gösterim, her pikselin çevresindeki piksel komşuları ile karşılaştırılmasıyla oluşturulur. LBP doku tanımlayıcısını oluşturmanın ilk adımı, görüntüyü gri tonlamaya dönüştürmektir. Gri tonlamalı görüntüdeki her piksel için, merkez pikseli çevreleyen $\mathrm{r}$ boyutunda bir alan seçilir. Daha sonra bu merkez piksel için bir LBP değeri hesaplanır ve girişteki görüntüsüyle aynı genişlik ve yüksekliğe sahip çıtılar oluşturulur. Algoritma üzerinde işlem yapmadan önce algoritmayı eğitmek gerekmektedir. Eğitmek için tanıtmak istediğimiz insanların yüz görüntülerine sahip bir veri seti kullanmamız gerekmektedir. Ayrıca her görüntü için bir kimlik (kişinin numarası veya adı olabilir) ayarlamamız gerekmektedir. Algoritma, bu bilgileri giriş görüntüsünü tanımak ve sonucunda bir çıktı vermek için kullanmaktadır. Aynı kişinin resimleri aynı kimliğe sahip olmalıdır.

LBPH için oluşturulan histogram, eğitim veri kümesindeki her bir görüntüyü temsil etmek için 
kullanılmaktadır. $\mathrm{Bu}$ nedenle, bir giriş görüntüsü verildiğinde bu yeni görüntü için aynı adımlar izlenecektir ve görüntüyü temsil eden bir histogram oluşturulacaktır. Bu işlem her bir piksel için yapılarak tüm resmin toplam histogramı çıkarılacaktır. Kameradan yeni alınan görüntünün histogramı ile daha önceden oluşturulmuş görüntülerin histogramları karşılaştırılmaktadır. $\mathrm{Bu}$ şekilde yüz tanıma yapılmaktadır. $\mathrm{Bu}$ çalışmada $\mathrm{LBPH}$ üzerinde histogramları karşılaştırmak için Öklid uzaklığı yöntemi kullanılmıştır.

$D=\sqrt{\sum_{i=1}^{n}\left(\text { hist } 1_{i}-\text { hist } 2_{i}\right)^{2}}$

Denklem 3'de Öklid mesafesinin formülü gösterilmektedir. "D” Öklid mesafesini, "hist1" ilk histogram1, "hist2" diğer histogramı temsil ederek iki histogramın farkının kareleri alınmıştır. Aynı işlem i ile başlayıp $n$ değeri olan toplam histogram sayısına kadar devam etmektedir. Son olarak bu işlemin tamamı karekök içerisine alınmıştır [20, 35-37].

\section{2. Çalışmada Oluşturulan ve Kullanılan Veri Seti (The Data Set Created and Used in the Study)}

Projenin ilk aşaması olan veri seti oluşturma kısmında, kullanıcıdan veri tabanına yüzünü kaydetmeden önce giriş değeri olarak benzersiz bir ID numarası girmesi istenir ve bu ID numarasıyla belirlenen frame sayısı göre kullanıcının 30, 60 veya 90 adet fotoğrafi çekilmektedir. Bu işlem Şekil 2'de gösterilmektedir. Fotoğraf sayısının artması veya azalması sistemin doğruluk oranını etkilemektedir.

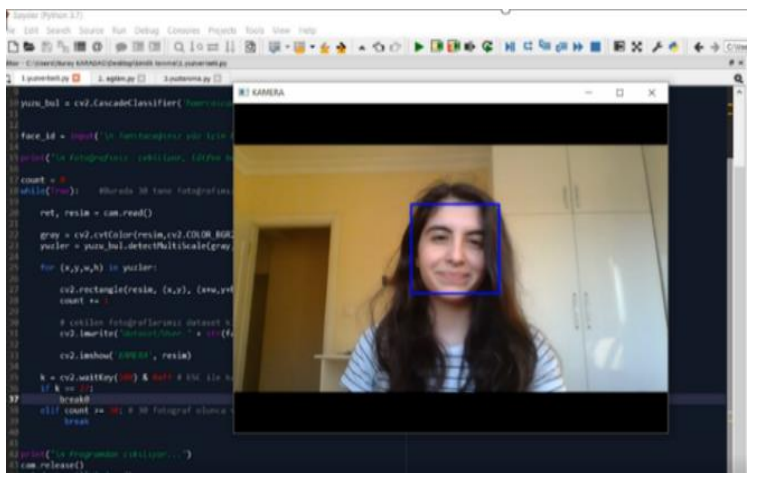

Şekil 2. Projenin ilk adımı (First step of the project)

Çekilen bu resimler, yazılımın bulunduğu aynı klasör içerisinde yer alan dataset isimli klasöre ID numarası ve kaçıncı fotoğraf olduğunu belirten numarayla birlikte ".jpeg" dosya türünde kaydedilmektedir. Algoritma içerisinde yüzün varlığı tespit ederek çerçeve içerisine alınan fotoğraflar gri tonlamaya çevrilerek veri tabanına kaydedilmektedir. Gri tonlamaya çevrilmesi hem GPU açısından hem de zaman açısından faydalıdır. Bu şekilde hızlıca veri seti oluşturulur. Bu işlem Şekil 3'te gösterilmektedir.

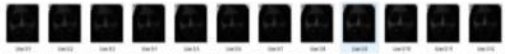 -

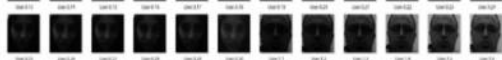

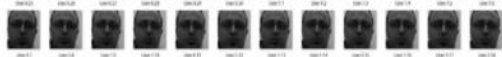

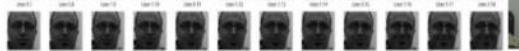

Şekil 3. Veri seti ve yüz tanıma ekranı (Data set and face recognition screen.)

$\mathrm{Bu}$ çalışma içerisinde Radboud (RaFD) yüz veri seti 67 kişiden alınmıştır. Bu veri setinin demografik yapısı farklı milletlerden (Kafkasyalı erkekler ve kadınlar, Kafkasyalı hem kız hem de erkek çocuklar ve Faslı erkekler) oluşmaktadır. Bu veri seti, sekiz farklı duygunun gösterildiği yüz ifadelerini içermektedir. Şekil 4 üzerinde bu yüz ifadeleri gösterilmiştir. Veri seti içindeki duygular; öfke, iğrenme, korku, mutluluk, üzüntü, şaşkınlık, aşağılama ve doğal yüz ifadeleridir. Her duygu ifadesi modellerin üç farklı bakış açısıyla (sağ, sol ve ön) oluşturulmuştur [38].

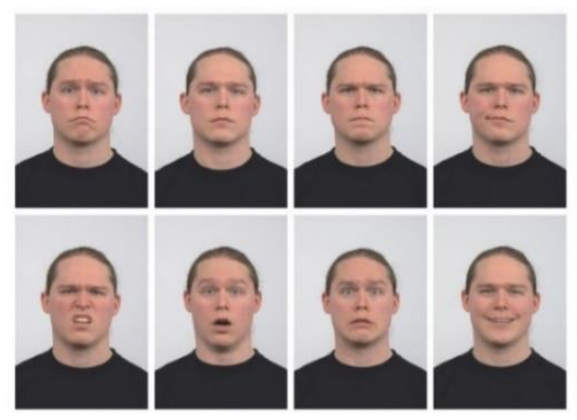

Şekil 4. Radboud (RaFD) yüz veri setinin içeriği yüz ifadeleri

Yazılım içerisinde oluşturulan veri setinde yazarlardan Nuray Karadağ ve Ali Çetinkaya'nın resimleri bulunmaktadır. Yazılımda deneylere çeşitlilik kazandırmak amacıyla yazılım içerisinde oluşturulan veri setine Radboud (RaFD) [38] veri seti içerisinden örnekler alınmıştır. Alınan orijinal resimler üzerinden eğitilen sistemin denemeleri uygulamalar bölümünde yapılmıştır.

\subsection{Sistemin Akış Diagramı (Flow Chart of the System)}

Şekil 5'te sistemin akış diyagramı verilmiştir. Proje akışına bakıldığında ilk olarak kamera açılmakta ve HaarCascade.xml dosyası çalıştırılmaktadır. Sonrasında kamera karşısındaki kişinin 30 adet fotoğrafinı çekip, çekilen fotoğraflardan kullanıcının veri seti oluşturulmaktadır. 


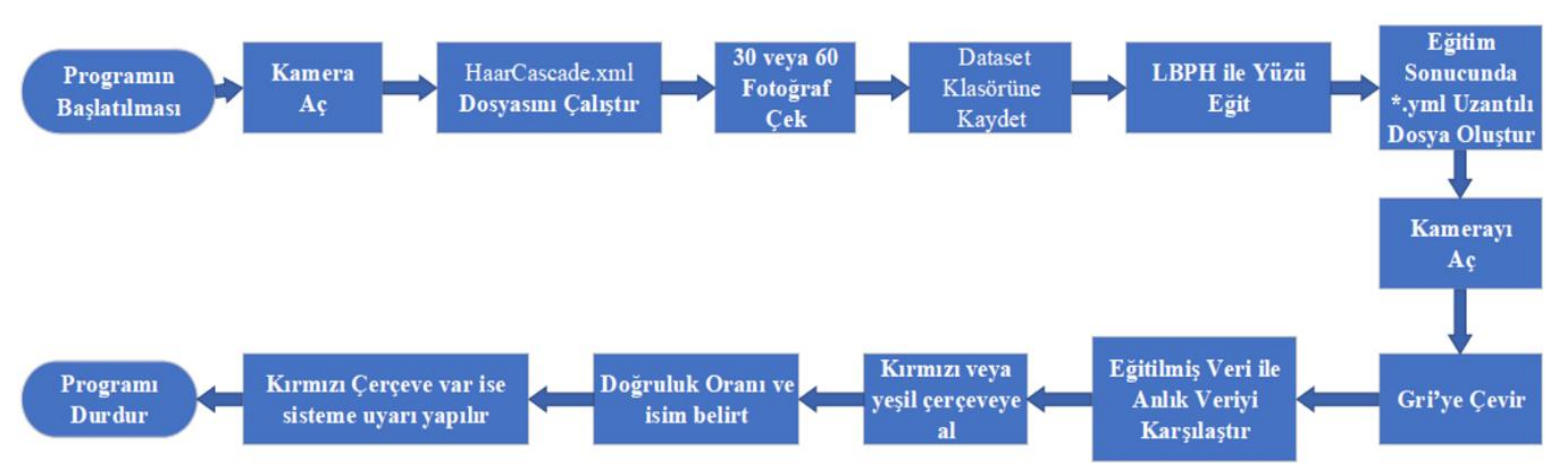

Şekil 5. Sistemin Akış Diyagramı (Flow Chart of the System)

Böylelikle Covid-19 şüphesi taşıyan kişilerin veri setleri kolaylıkla oluşturulmaktadır. Çekilen fotoğraflar LBPH ile eğitilerek ".yml” uzantılı bir dosya oluşturulmaktadır. Bu kayıt sonucunda kamera açılmakta ve kişinin resmi gri tonlamaya çevrilmektedir. Çevrilmiş olan resim eğitilmiş veri ile karşılaştırılıp sonuç ekranda gösterilmektedir. Eğer kişinin yüzü veri setinde varsa bu kişinin virüs taşıdığını belirtmekte ve kırmızı çerçeve ile gösterilmektedir. Eğer kişinin yüzü veri setinde yoksa çerçeve yeşil renkli olmaktadır. Daha sonrasında kişinin ismi ve anlık doğruluk oranı ekranda gösterilmektedir. Son durumda kişinin yüzü kırmızı çerçeve içerisine alınmış ise gerekli kurum ve kuruluşlara e-posta ile bilgilendirilme yapılmaktadır. $\mathrm{Bu}$ işlemler sonunda süreçler tekrar ederek, kişilerin yüzleri ve yaptığ ihlaller tespit edilebilmektedir.

\section{UYGULAMALAR (APPLICATIONS)}

Geliştirilmiş olan yazılım, Covid-19 tanılı kişilerin kayıt, tespit ve bildirim sistemi günlük hayatta şehir içi ve şehir dışı mobese kameraları, sokaklarda bulunan kameralar, toplu taşıma araçlarında bulunan kameralar başta olmak üzere kameraların bulunduğu her alanda kullanılabilecektir. Hastalıklı olarak tanımlanacak kişilerin sokağa çıkma yasağını ihlal etmeleri ve kendi alanlarını terk etmeleri durumunda gerekli kurumlara ve yetkili kişilere, kişinin kimlik bilgileriyle birlikte görüldüğü tarih ve saat bilgileri eposta yoluyla gönderilmektedir. Yapılan testlerde hata oranını en aza indirmek için farklı ortam ve 1 şıkta incelemeler gerçekleştirilmiştir. Uygulamanın testlerinin, tanıma işlemindeki doğruluğunun tespit edilmesi için kamusal alanlarda gerçekleştirilmesi hedef alınmış ancak pandemi dolayısıyla gerçekleştirilememiştir.
Yazılım içine eklenecek veri seti (Radboud (RaFD) ile uygulamalar ve sonuçlar arttırılmıştır. $\mathrm{Bu}$ veri setindeki kişiler hastanelerin hasta kayıt sistemi örnek alınarak tasarlanmıştır. Hasta kayıt sisteminde hastaların kimlik bilgileri ve kimlik üzerindeki fotoğrafları kaydedilebilmektedir. Bu yüzden kayıt esnasında oluşturulan veri setindeki kişiler veri tabanında hastalık taşıyor olarak etiketlenmektedir. Etiketlenmeyen kişiler uygulama içerisinde yeşil çerçeve ile görüntülenmektedir. Kameradan veri tabanına kayıtlı tek kişinin görüntülenmesi Şekil 6' da gösterilmektedir.

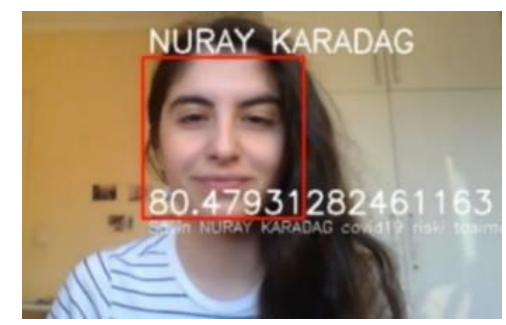

Şekil 6. Çok Işıklı Ortamda Yüz Tanıma (Facial recognition in a multi-light environment)

Projenin son aşamasının ilk bölümü olan yüz tanıma kısmında da eğitilmiş olan verilerle kameradan alınan veriler karşılaştırılarak doğruluk oranıyla ekranda belirtilmektedir. Eğer kişi daha önceden tanıtılmışsa ismi ve doğruluk oranıyla birlikte ekranda kırmızı çerçeve içerisinde "virüs riski taşımaktasınız" yazısıyla ekranda gösterilir eğer önceden tanıtılmamışsa yeşil çerçeveye alınarak "tanınmadı" ve "virüs riski taşımamaktasınız" yazısıyla birlikte ekranda gösterilir. Şekil 7'de 30, 60 ve 90 frame ile gerçekleştirilmiş deneyler ve ekran çıtıları verilmiştir. Ayrıca gerçekleştirilen deneylerin sonuçları Tablo 4'te detaylı verilmiştir. 


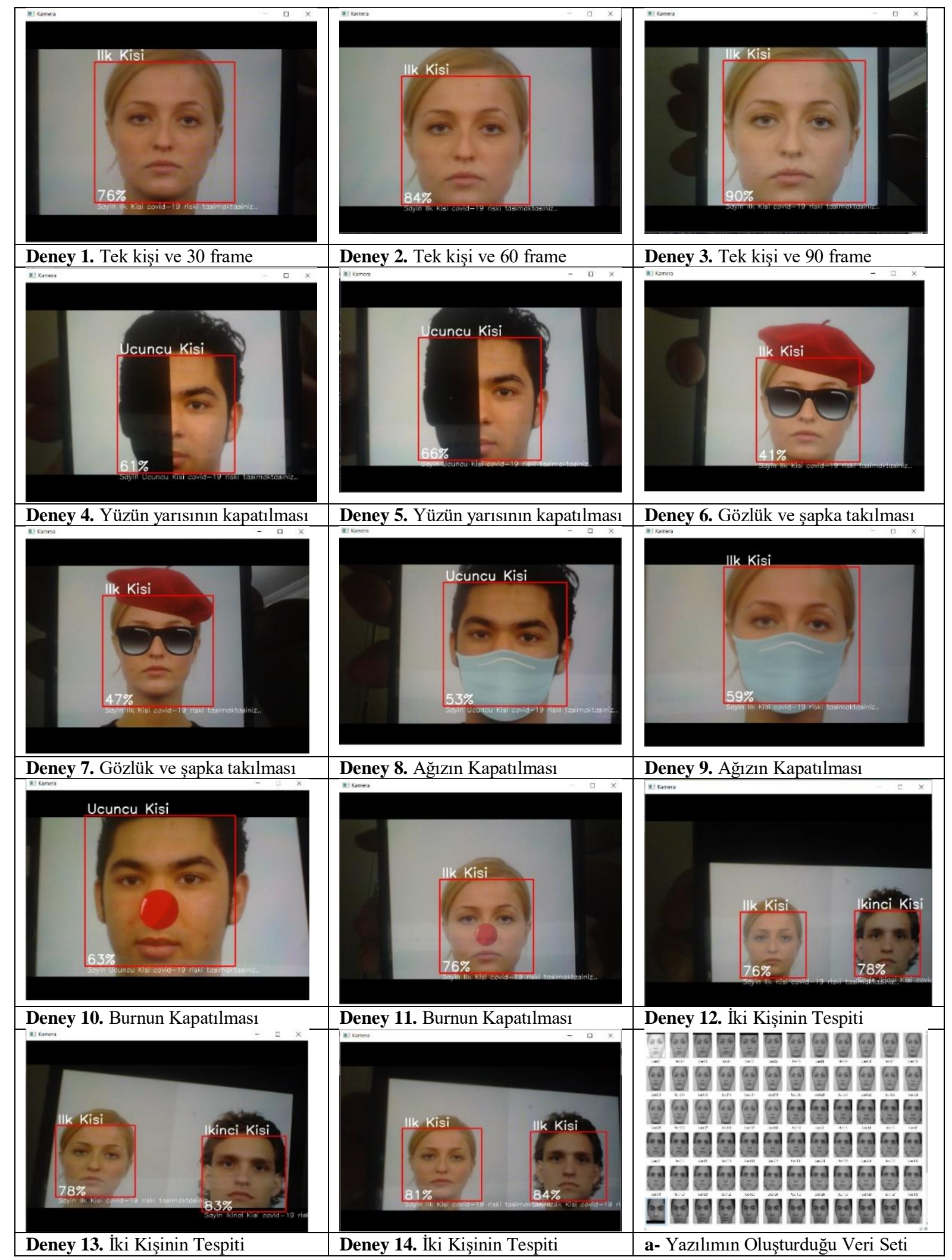

Şekil 7. Yazılım üzerinde gerçekleştirilen 14 deney ve veri setinden görüntüler (Figure 8. Images from 14 experiments and data sets performed on the software.) 


\section{SONUÇLAR (RESULTS)}

Tablo 3. Literatür taramasının değerlendirilmesi (Evaluation of literature review.)

\begin{tabular}{|c|c|c|c|c|c|}
\hline $\begin{array}{l}\text { Literatür } \\
\text { Adı }\end{array}$ & $\begin{array}{c}\text { Kullanılan } \\
\text { Teknik }\end{array}$ & $\begin{array}{c}\text { Kullanılan Algoritma } \\
\text { Tipi }\end{array}$ & $\begin{array}{c}\text { Kullanılan Veri } \\
\text { Seti ve Resim } \\
\text { Sayısı }\end{array}$ & $\begin{array}{c}\text { Alınan } \\
\text { Başarı } \\
\text { Sonucu }\end{array}$ & $\begin{array}{l}\text { Alınan } \\
\text { Hata } \\
\text { Sonucu }\end{array}$ \\
\hline Kekül, (2018) & Derin Öğrenme & Yapay sinir ağları (YSA) & $\begin{array}{l}\text { The Database of Faces- } \\
400\end{array}$ & 98,7 & 1,3 \\
\hline Mamak, (2020) & Derin Öğrenme & Yerel İkili Örüntü (LBP) & $\begin{array}{c}\text { Çalışma içerisinde } \\
\text { veriseti bilgisine } \\
\text { ulaşılamamıştır }\end{array}$ & 94,32 & 5,28 \\
\hline $\begin{array}{l}\text { Nabiyev, } \\
(2010)\end{array}$ & Derin Ö̆grenme & $\begin{array}{l}\begin{array}{l}\text { Yönelimli } \\
\text { (HOG) }\end{array} \\
\end{array}$ & FERET - 846 & 93,91 & 6,09 \\
\hline $\begin{array}{c}\text { Rodriguez, } \\
(2006)\end{array}$ & Derin Öğrenme & Yerel İkili Örüntü (LBP) & $\begin{array}{l}\text { XM2VTS database - } \\
200 \\
\end{array}$ & 90 & 10 \\
\hline Karadag,(2020) & Derin Öğrenme & Yerel İkili Örüntü (LBP) & Radboud (RaFD)-210 & 84,5 & 20 \\
\hline $\begin{array}{c}\text { Özdemir, } \\
(2019)\end{array}$ & Derin Ö̆grenme & Evrişimli Sinir Ağ $1(\mathrm{CNN})$ & Ridnet -10989 & 80 & 20 \\
\hline Atasoy, (2018) & Derin Öğrenme & Destek Vektör & $\begin{array}{c}\text { Çalışma içerisinde } 20 \\
\text { test verisi ile alınan } \\
\text { sonuçlar } \\
\end{array}$ & 80 & 20 \\
\hline
\end{tabular}

Tablo 3 'te yer alan bilgiler literatür taramasında incelenmiş projelerdir. Tabloda yer alan bilgiler projede kullanilan yöntemler ve bu yöntemlerin doğruluk oranlarıdır. Yapılan literatür taraması sonucunda gerçekleştirilen projeler detaylı olarak incelenmiş ve bu inceleme sonucunda insan yüzünü tanıyabilen bir proje oluşturulmuştur. Farklı kişiler üzerinde ve farklı 1 şı değerlerinde testler yapılmış, testler neticesinde geliştirilen projede $\% 84,5$ oranında doğruluk tespit edilmiştir. Gerçekleştirilmiş olan bu çalışmada toplam 14 adet deney yapılmıştır. $\mathrm{Bu}$ deneyde farklı işlemler uygulanarak sistemin başarısının ve hatasının testleri gerçekleştirilmiştir. Yapılan deneylerde LBPH yöntemi kullanılıp frame sayısı değiştirilerek uygulamalar tekrarlanmıştır. Tabloda yer alan deneylerin sonuçları alınan maksimum değerlerdir.

Tablo 4. Gerçekleștirilen deneylerin değerlendirilmesi (Evaluation of the experiments performed)

\begin{tabular}{|l|l|l|l|l|}
\hline $\begin{array}{l}\text { Deney } \\
\text { No }\end{array}$ & $\begin{array}{l}\text { Anlık Frame } \\
\text { Sayısı }\end{array}$ & Yapılan İşlem & $\begin{array}{l}\text { Alınan Başarı } \\
\text { Sonucu }\end{array}$ & $\begin{array}{l}\text { Alınan } \\
\text { Payı }\end{array}$ \\
\hline $\mathbf{1}$ & 30 & Tek kişinin Yüzünün Algılanması & $\% 76$ & $\% 24$ \\
\hline $\mathbf{2}$ & 60 & Tek kişinin Yüzünün Algılanması & $\% 84$ & $\% 16$ \\
\hline $\mathbf{3}$ & 90 & Tek kişinin Yüzünün Algılanması & $\% 90$ & $\% 10$ \\
\hline $\mathbf{4}$ & 30 & Yüzün Yarısının Farklı Cisimle Kapatılması & $\% 61$ & $\% 39$ \\
\hline $\mathbf{5}$ & 60 & Yüzün Yarısının Farklı Cisimle Kapatılması & $\% 66$ & $\% 36$ \\
\hline $\mathbf{6}$ & 30 & Gözlük ve Şapka Takılması & $\% 41$ & $\% 59$ \\
\hline $\mathbf{7}$ & 60 & Gözlük ve Şapka Takılması & $\% 47$ & $\% 53$ \\
\hline $\mathbf{8}$ & 30 & Ağız, Göz Gibi Yüz Hatlarının Kapatılması & $\% 53$ & $\% 47$ \\
\hline $\mathbf{9}$ & 60 & Ağı, Göz Gibi Yüz Hatlarının Kapatılması & $\% 59$ & $\% 41$ \\
\hline $\mathbf{1 0}$ & 30 & Burunun Kapatılması & $\% 63$ & $\% 37$ \\
\hline $\mathbf{1 1}$ & 60 & Burunun Kapatılması & $\% 76$ & $\% 24$ \\
\hline $\mathbf{1 2}$ & 30 & 2 Kişinin Aynı Anda Tanıtılması ve Analizi & $\% 76-\% 78$ & $\% 24-\% 22$ \\
\hline $\mathbf{1 3}$ & 60 & 2 Kişinin Aynı Anda Tanıtılması ve Analizi & $\% 78-\% 83$ & $\% 22-\% 27$ \\
\hline $\mathbf{1 4}$ & 90 & 2 Kişinin Aynı Anda Tanıtılması ve Analizi & $\% 81-\% 84$ & $\% 19-\% 16$ \\
\hline
\end{tabular}


Deney 1'de 30 frame ile tek kişinin yüzü tanıtılmıştır. Alınan başarı sonucu \%76 olmakla birlikte hata oranı \%24 tür. Deney 2'de 60 frame ile yine tek kişinin yüzü tanıtılmış, başarı sonucu $\% 84$, hata oran $1 \% 16$ olarak hesaplanmıştır. Deney 3'de 90 frame ile tek kişinin yüzü tanıtılmış, başarı sonucu $\% 90$, hata oranı \%10 olarak hesaplanmıştır. Deney 4'te ise 30 frame ile yüzün yarısı kapatılıp yüz tanıtılmıştır, alınan başarı oranı \%61, hata oranı \%39 dur. Deney 5 'de ise 60 frame ile yüzün yarısı kapatılıp yüz tanıtılmıştır, alınan başarı oranı \%66, hata oranı $\% 34$ dür. Deney 6'da 30 frame ile gözlük ve şapka takılarak yüz tanıtılmıştır, alınan başarı oranı $\% 41$, hata oran1 \%59 dur. Deney 7'de 60 frame ile yine gözlük ve şapka takılarak yüz tanıtılmıştır, alınan başarı oranı $\% 47$, hata oran1 \%53 tür. Deney 8 'de 30 frame ile ağız, göz gibi yüz hatları kapatılarak yüz tanıtılmıştır, alınan başarı oranı $\% 53$, hata oranı $\% 47$ dir. Deney 9' da 60 frame ile yine belirgin hatlar kapatılıp yüz tanıtılmıştır, başarı oranı $\% 60$ hata oranı $\% 40$ tır. Deney 10'da 30 frame ile burun kapatılarak tanıtılan yüzden alınan başarı oranı $\% 63$, hata oranı
\%37 dir. Deney 11'de 60 frame ile burun kapatılarak tanıtılan yüzden alınan başarı sonucu $\% 76$, hata oranı \%24 tür. Deney 12'de iki kişi aynı anda tanıtılarak, kişilerin ayrı ayrı 30 frame görüntüsü alınmıştır, başarı oranı $\% 76$ - \%78 aralığındadır, hata oranı $\% 24$ - \%22 dir. Deney 13'te yine iki kişinin ayrı 60 frame görüntüsü alınmış, başarı oranı $\% 78$ - $\% 83$, hata oranı $\% 22$ - \%17 dir. Deney 14'te 90 frame ile iki kişi tanıtılarak elde edilen başarı oranı $\% 81$ - \%84, hata oranı \%19 - \%16 aralığındadır.

$\mathrm{Bu}$ deney sonuçlarından da anlaşılacağı üzere bir kişinin kesin olarak tanınması \%75 ve üzere doğruluk değerine sahip ise gerçekleşmektedir. Bununla beraber sistem geliştirilip hastalık taşıyan kişi ne zaman ihlal yaptı, kimlerle temas etti, kimler ile iletişimde bulunda gibi bilgiler kolayca tespit edilip yayılma hızı oldukça yavaşlatılacaktır. Şekil 8 üzerinde yazılımın gönderdiği bilgilendirme mesajını ekran görüntüsü verilmiştir.

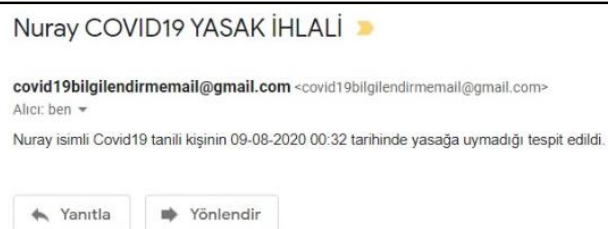

Şekil 8. Bilgilendirme mesajı içeriği (Content of information message)

\section{ARAŞTIRMA BULGULARI VE TARTISSMALAR (THE RESEARCH FINDINGS AND DISCUSSION)}

Geliştirilen projede program içerisinden belirlenen e-posta adresine bilgilendirme e-postası atılmas1 işlemi, sunucu üzerinden iletişim protokolleri kullanılarak daha işlevsel hale getirilebilir. Yüz tanıma yapılırken bilgisayar kamerası yerine harici ve daha donanımlı bir kamera kullanılarak daha iyi sonuçlar alınabilir. İki ayrı veri seti oluşturulup tanınmamış kişilerin de kaydı tutulabilir ve KVKK'ya uygun olarak daha çok yüz tanıtılarak veri setinde çeşitlilik sağlanabilir. Iş̧k yoğunluğunun gün içerisinde değişmesinden etkilenmeyen bir ortamda art arda fotoğraf çekilme işlemleri yapılarak daha iyi sonuçlar elde edilebilir. Bununla birlikte duruş farklılıklarından kaynaklı olarak yüz tanıma oranları değişiklik gösterdiği için yüz tanıma yapılırken aynı zamanda retina taraması yapılması sistemin daha güçlü hale getirilmesini sağlayabilir.

Veri seti güvenlik yamaları yapılarak daha korunaklı bir veri tabanında tutulabilir. Veri setinde çeşitlilik olması için kişilerin gözlüklü-gözlüksüz, sakallı-sakalsız halleri ile farklı boyutlarda resimleri çekilebilir ya da yeni teknolojiler kullanarak bu farklılıkların tanıma oranlarını etkilemeyen algoritmalar kullanılabilirdi. Google COLAB kullanılarak daha iyi GPU kaynağına sahip olarak hem sistemin hem de algoritmanın çalışmasına destek olarak daha hızlı bir şekilde işlemler gerçekleştirilebilirdi.

Sistemin daha işlevsel hale getirilmesi ve vaka sürecinde hızla yol kat edilebilmesi amacıyla Sağlık Bakanlığı, Emniyet Genel Müdürlüğü ve belediyelerle ortak çalışma gerçekleştirilerek sistemin uygulanması yolunda çalışmalar yapılabilirdi. Bu çalışmaların yapılması uygulamanın kullanılabilirliği açısından önemli bir adım olacaktır.

\section{ÇIKAR ÇATIŞMASI BİLDİRİMİ (CONFLICT OF INTEREST STATEMENT)}

Yazarlar tarafindan herhangi bir çıkar çatışması bildirilmemiştir.

\section{KAYNAKLAR (REFERENCES)}

[1] T.C. Sağlık Bakanlığı, "COVID-19 (Yeni Koronavirüs Hastalığı) Nedir?," saglik.gov.tr, Jun. 3, 
$2020 . \quad$ [Online]. Available: https://covid19bilgi.saglik.gov.tr/tr/covid-19-yenikoronavirus-hastaligi-nedir.html. [Accessed: Jul. 08, 2020].

[2] T.C. Sağlık Bakanlığı Halk Sağlığ1 Genel Müdürlüğü, "Covid-19 (Sars-Cov-2 Enfeksiyonu) Genel Bilgiler, Epidemioloji ve Tani," saglik.gov.tr, Jun. 4, 2020. [Online]. Available: https://covid19bilgi.saglik.gov.tr/depo/rehberler/covi d-19-rehberi/covid-

19_rehberi_genel_bilgiler_epidemiyoloji_ve_tani.pdf . [Accessed: Jul. 08, 2020].

[3] T.C. Sağlık Bakanlığı Halk Sağlığı Genel Müdürlüğü, "Temasli Takibi, Salgın Yönetimi, Evde Hasta İzlemi ve Filyasyon,", saglik.gov.tr, Jun. 4, 2020. [Online]. Available: https://covid19bilgi.saglik.gov.tr/depo/rehberler/covi d-19-rehberi/covid-

19_rehberi_temasli_takibi_evde_hasta_izlemi_ve_fil yasyon.pdf. [Accessed: Jul. 07, 2020].

[4] M. Roser, H. Ritchie, E. Ortiz-Ospina and J. Hasel, "Coronavirus disease (COVID-19)-Statistics and research.", 2020, [online]. Available: https://ourworldindata.org/covid-cases\#what-is-thetotal-number-of-confirmed-cases, [Accessed: Jul. 01, 2020].

[5] Covid-19 Coronavirus Pandemic, "Coronavirus Cases:", 2020, [Online]. Available: https://www.worldometers.info/coronavirus/ [Accessed: Nov. 10, 2020].

[6] M. M. Yapıcı, A. Tekerek and N. Topaloğlu, "Literature Review of Deep Learning Research Areas," Gazi Mühendislik Bilimleri Dergisi (GMBD), vol. 5, no. 3, pp. 188-215, 2019. doi: 10.30855/gmbd.2019.03.01

[7] N. Aalami, "Derin Öğrenme Yöntemlerini Kullanarak Görüntülerin Analizi," Eskişehir Türk Dünyası Uygulama ve Araştırma Merkezi Biliş̧im Dergisi, vol. 1, no. 1, pp. 17-20, 2020.

[8] R. Özdemir and M. Koç, "Yeni Bir Veri Kümesi (RidNet) Kullanarak Kontrolsüz Ortamda Yüz İfadesi Tanımanın Derin Öğrenme Yöntemleri ile İyileştirilmesi," Bilecik Şeyh Edebali Üniversitesi Fen Bilimleri Dergisi, vol. 6, no. 2, pp. 384-396, 2019. doi: 10.35193/bseufbd.645138
[9] I. Fasel, B. Fortenberry and J. Movellan, "A Generative Framework for Real Time Object Detection and Classification," Computer Vision and Image Understanding, vol. 98, no. 1, pp. 182-210, 2005. doi: 10.1016/j.cviu.2004.07.014

[10] N. Yalçın and F. Gürbüz, "Biyometrik Güvenlik Sistemlerinin İncelenmesi," Düzce Üniversitesi Bilim ve Teknoloji Dergisi, vol. 3, no. 2, pp. 398-413, 2015.

[11] E. Dandıl, M. Turkan, M. Boğa and K. K. Çevik, "Daha Hızlı Bölgesel-Evrişimsel Sinir Ağları ile Sığır Yüzlerinin Tanınması," Bilecik Şeyh Edebali Üniversitesi Fen Bilimleri Dergisi, vol. 6, pp. 177189, 2019. doi: 10.35193/bseufbd.592099

[12] F. Bayram, "Derin Öğrenme Tabanlı Otomatik Plaka Tanıma," Politeknik Dergisi, vol. 23, no. 4, pp. 955-960, 2020. doi: 10.2339/politeknik.515830

[13] M. Toğaçar, B. Ergen and M. E. Sertkaya, "Zatürre Hastalığının Derin Öğrenme Modeli ile Tespiti," Firat Üniversitesi Mühendislik Bilimleri Dergisi, vol. 31, pp. 223-230, 2019.

[14] V. Vansh, K. Chandrasekhar, C. R. Anil and S. S. Sahu, "Improved Face Detection Using $\mathrm{YCbCr}$ and Adaboost," Computational Intelligence in Data Mining, pp. 689-699, 2020. doi: 10.1007/978-981-138676-3_58

[15] H. Kekül, H. Bircan and H. Arslan, "Yüz Tanıma Uygulamalarinda Özyüzler ve Yapay Sinir Ağlarının Karşılaştırılması," Uluslararası Yönetim Bilişim Sistemleri Ve Bilgisayar Bilimleri Dergisi, vol. 2, no. 1, pp. 51-59, 2018.

[16] U. Mamak, M. Z. Konyar, S. Solak and M. H. Uçar, "Gerçek Zamanlı Yüz Tanıma Tabanlı Personel Kontrol ve Takip Sistemi Tasarımı," Avrupa Bilim ve Teknoloji Dergisi, vol. 19, pp. 497-504, 2020. doi: 10.31590/ejosat. 727768

[17] N. A. Atasoy and D. Tabak, "Destek Vektör Makineleri Kullanarak Yüz Tanıma Uygulaması Geliştirilmesi," Engineering Sciences, vol. 13, no. 2, pp. 119-127, 2018. doi: 10.12739/NWSA.2018.13.2.1A0406

[18] D. Terzopoulos and K. Waters, "Analysis of facial images using physical and anatomical models," Proceedings Third International Conference on Computer Vision, IEEE Computer Society, 1990. doi: 10.1109/ICCV.1990.139628 
[19] M. Kirby and L. Sirovich, "Application of The Karhunen-Loeve Procedure for The Characterization of Human Faces," IEEE Transactions on Pattern Analysis and Machine Intelligence, vol. 12, no. 1, pp. 103-108, 1990. Doi: 10.1109/34.41390

[20] Y. Rodriguez and S. Marcel, "Face Authentication Using Adapted Local Binary Pattern Histograms," European Conference on Computer Vision, 2006. Doi: 10.1007/11744085_25

[21] G. Gündüz and İ. H. Cedimoğlu, "Derin Öğrenme Algoritmalarını Kullanarak Görüntüden Cinsiyet Tahmini," Sakarya University Journal of Computer and Information Sciences, vol. 2, no. 1, pp. 9-17, 2019. doi: 10.35377/saucis.02.01.517930

[22] S. Toraman, "Derin Öğrenme ile İnsansız Hava Arac1 Görüntülerinden Yaya Tespiti," Journal of Aviation, vol. 2, no. 2, pp. 64-69, 2018. doi: 10.30518/jav. 450913

[23] H. T. Ngo, R. N. Rakvic, R. P. Broussard and R. W. Ives, "An FPGA-Based Design of a Modular Approach for Integral Images In A Real-Time Face Detection System," Mobile Multimedia/Image Processing, Security and Applications 2009, vol. 7351, 2009. doi: $10.1117 / 12.820248$

[24] S. Çam and S. B. Kılıç, "Altın Fiyatı Günlük Getirilerinin Yapay Sinir Ağları Algoritması ve Markov Zincirleri Modelleri ile Tahmini," Uluslararası Iktisadi ve İdari İncelemeler Dergisi, vol. 18, pp. 681-694, 2018. doi: 10.18092/ulikidince. 347048

[25] H. Söyler and O. Kızılkaya, "Para Krizlerinin Yapay Zeka Yöntemleri İle Tahmini: Türkiye Örneği," Uluslararası İktisadi Ve İdari İncelemeler Dergisi, vol. 18, pp. 649-666, 2018. doi: 10.18092/ulikidince.347202

[26] D. Onocak and S. Koç, "Yapay Sinir Ağlari İle Emeklilik Yatirim Fonu Hisse Senedi Fiyatlarinin Tahmini," Finans Ekonomi Ve Sosyal Araştırmalar Dergisi (Fesa), vol. 3, no. 3, pp. 590-600, 2018. doi: 10.29106/fesa. 450623

[27] Ö. Çelik and U. Ö. Osmanoğlu, "Prediction of The Prices of Second-Hand Cars," Avrupa Bilim ve Teknoloji Dergisi, vol. 16, pp. 77-83, 2019. doi: 10.31590/ejosat.542884

[28] F. Doğan and İ. Türkoğlu, "Derin Öğrenme Modelleri ve Uygulama Alanlarına İlişkin Bir Derleme," Dicle Üniversitesi Mühendislik Fakültesi
Mühendislik Dergisi, vol. 10, no. 2, pp. 409-445, 2019. doi: 10.24012/dumf.411130

[29] R. Daş, B. Polat and G. Tuna, "Derin Öğrenme ile Resim ve Videolarda Nesnelerin Tanınması ve Takibi," Firat Üniversitesi Mühendislik Bilimleri Dergisi, vol. 31, no. 2, pp. 571-581, 2019. doi: 10.35234/fumbd.608778

[30] A. Şeker, B. Diri and H. H. Balık, "Derin Öğrenme Yöntemleri ve Uygulamaları Hakkında Bir İnceleme," Gazi Mühendislik Bilimleri Dergisi, vol. 3, no. 3, pp. 47-64, 2017.

[31] M. Toğaçar and B. Ergen and F. Özyurt, "Evrişimsel Sinir Ağı Modellerinde Özellik Seçim Yöntemlerini Kullanarak Çiçek Görüntülerinin Sinıflandırılması," Firat Üniversitesi Mühendislik Bilimleri Dergisi, vol. 32, no. 1, pp. 47-56, 2020. doi: 10.35234/fumbd.573630

[32] A. Arı and M. E. Berberler, "Yapay Sinir Ağları ile Tahmin ve Sınıflandırma Problemlerinin Çözümü İçin Arayüz Tasarımı," Acta Infologica, vol. 1, no. 2, pp. 55-73, 2017.

[33] H. Üzen and K. Hanbay, "Yaya Özellik Tanıma İçin LM Filtre Temelli Derin Evrişi̇msel Sinir Ağı," Politeknik Dergisi, vol. 23, pp. 605-613, 2020. doi: 10.2339/politeknik.525600

[34] F. Özyurt and E. Avcı, "İmge Sınıflandırması için Yeni Öznitelik Çıkarım Yöntemi: Add-Tda Algısal Özet Fonksiyonu Tabanlı Evrişimsel Sinir Ağ (AddTda-Esa)," Türkiye Bilişim Vakfi Bilgisayar Bilimleri ve Mühendisliği Dergisi, vol. 12, no. 1, pp. 30-38, 2019.

[35] V. V. Nabiyev and A. Günay, "LBP Yardımıyla Görüntüdeki Kişinin Yaşının Bulunması," Çankaya Üniversitesi Bilim ve Mühendislik Dergisi, vol. 8, no. $1,2010$.

[36] C. H. Chan, J. Kittler and K. Messer, "MultiScale Local Binary Pattern Histograms for Face Recognition," Advances in Biometrics, vol. 4642, 2007. doi: 10.1007/978-3-540-74549-5_85

[37] T. Ahonen, J. Matas, C. He and M. Pietikäinen, "Rotation Invariant Image Description with Local Binary Pattern Histogram Fourier Features," Scandinavian Conference on Image Analysis, vol. 5575, 2009. doi: 10.1007/978-3-642-02230-2_7 
[38] O. Langner, R. Dotsch, G. Bijlstra, D. H. J. Wigboldus, S. T. Hawk and A. V. Knippenberg, "Presentation and Validation of The Radboud Faces Database," Cognition and Emotion, vol. 24, no. 8, pp. 1377-1388, 2010. doi: 10.1080/02699930903485076

\section{Nuray KARADA $\breve{G}$}

Yazar İstanbul doğumludur. 2005 yılında İnönü İlkokulu'na başlayıp 2012 yllında mezun olmuştur. Aynı yıl başladığım Barbaros Anadolu Lisesi'nden, son sene ayrilarak Birey Temel Lisesinden 2016 yılında mezun olmuştur. 2016 yılında İstanbul Gelişim Üniversitesi Bilgisayar Mühendisliği bölümüne başlayıp, Temmuz 2020 'de mezun olmuştur. Geleceğin mesleği olan yapay zekâ alanına kendini geliştirmek için çalışmalar yapmaktadır.

\section{Ali ÇETINKAYA}

Yazar Ankara doğumludur. 2014 yllında lisans eğitimini Selçuk Üniversitesi Teknik Eğitim Fakültesinde Elektronik Öğretmenliği bölümünde tamamlamıştır. Daha sonra 2017 yılında KTO Karatay Üniversitesi Fen Bilimleri Enstitüsü Elektrik ve Bilgisayar Mühendisliği Anabilim Dalında Yüksek Lisans eğitimini tamamlamıştır. 2017 yılında Araştırmacı olarak İstanbul Gelişim Üniversitesi Teknoloji Transfer Ofisi Uygulama ve Araştırma Merkezi'nde göreve başlamıştır. Araştırma alanları arasında Gömülü Sistemler, Yapay sinir ağları, Bulanık Mantık, Otonom sistemler ve Proje geliştirme ve yönetimi konularında çalışmalar yapmaktadır.

\section{Hakan AYDIN}

Yazar Edirne doğumludur. 1993 yılında lisans eğitimini Elektronik Mühendisliği bölümünde, 2003 yılında birinci Yüksek Lisansını Yazılım Mühendisliğinde, 2005 yllında ikinci Yüksek Lisansını Uluslararası İlişkiler alanında, 2017 yılında Doktorasını Hacettepe Üniversitesinde tamamlamıştır. Halen İstanbul Gelişim Üniversitesi Mühendislik ve Mimarlık Fakültesi Bilgisayar Mühendisliği Bölümünde öğretim üyesidir. Araştırma ilgi alanları arasında bulut bilişim, yapay zeka ve siber güvenlik konuları bulunmaktadır. 